\title{
A Cross-Cultural Study of Relationships between Epistemological Beliefs and Self-Regulated Learning Strategies
}

\section{Ying Hong Jiang ${ }^{1}$, Jia Wang ${ }^{2}$, Patricia Bonner ${ }^{1}$, Jenny Yau ${ }^{1}$}

${ }^{1}$ Azusa Pacific University

${ }^{2}$ University of California, Los Angeles

\section{Estados Unidos}

Correspondence: Ying Hong Jiang, Department of Education Leadership, School of Education, Azusa Pacific University, US. E-mail: yjiang@apu.edu

(C) Universidad de Almería and Ilustre Colegio Oficial de la Psicología de Andalucía Oriental (Spain) 


\section{Abstract}

Introduction. Prior research consistently provides evidence supporting potential relationships between epistemological beliefs and learning. The current study examines the relationship between epistemological beliefs, academic motivation, and self-regulated learning strategies among different ethnic groups of American adolescents.

Method. This quantitative study utilized a correlational design to examine the relationship between epistemological beliefs and self-regulated learning strategies in adolescents attending middle school. A total of 364 middle school students $\left(6^{\text {th }}\right.$ to $8^{\text {th }}$ grade) from Southern California public middle schools participated in the study. A multiple group path model was employed to analyze the student data.

Results. We found that certain knowledge, omniscient authority, and innate ability beliefs about the nature of knowledge predict positive relationships with self-efficacy and intrinsic value components of motivation. Quick learning and simple knowledge beliefs predict negative relationships with self-efficacy and intrinsic-value but positive relationship with testanxiety. Similarly, in the aspect of self-regulatory learning strategies, those who believe in the absolute nature of knowledge and the authorities tend to use cognitive and self-regulatory learning strategies more often, while those who believe in the speed of knowledge acquisition tend to employ those strategies less.

Discussion and Conclusion. Findings from this study inform educators of the need to advance adolescents' epistemological beliefs for each subject (e.g., science, language arts) as a method to facilitate their motivation and self-regulated learning. We recommend that future research should include assessments of the participants' cultural orientations or the domain specificity of the epistemological beliefs, which may vary the associations of the beliefs with self-regulated learning. Additionally, future research can further investigate other potential mediators of the relationship between epistemological beliefs and self-regulatory learning.

Keywords: Epistemological Beliefs, Self-Regulated Learning Strategies, Multiple Group Path Model, Middle School Students. 


\section{Resumen}

Introducción. Investigaciones anteriores proporcionan de manera constante evidencia que apoya las posibles relaciones entre las creencias epistemológicas y el aprendizaje. El presente estudio examina la relación entre las creencias epistemológicas, la motivación académica y las estrategias de aprendizaje autorregulado entre diferentes grupos étnicos de adolescentes estadounidenses.

Método. Este estudio cuantitativo utilizó un diseño correlacional para examinar la relación entre las creencias epistemológicas y las estrategias de aprendizaje autorregulado en adolescentes que asisten a la escuela secundaria. En el estudio participaron un total de 364 estudiantes de primaria y secundaria (sexto a octavo grado) de las escuelas públicas del sur de California. Se empleó un modelo de ruta de grupos múltiples para analizar los datos de los estudiantes.

Resultados. Descubrimos que cierto conocimiento, autoridad omnisciente y creencias de capacidad innata sobre la naturaleza del conocimiento predice relaciones positivas con la autoeficacia y los componentes de valor intrínseco de la motivación. Las creencias de aprendizaje rápido y conocimiento simple predicen relaciones negativas con la autoeficacia y el valor intrínseco, y predicen una relación positiva con la ansiedad ante los exámenes. Del mismo modo, en el aspecto de las estrategias de aprendizaje autorreguladoras, quienes creen en la naturaleza absoluta del conocimiento y las autoridades tienden a utilizar estrategias de aprendizaje cognitivo y autorregulado con mayor frecuencia, mientras que quienes creen en la velocidad de adquisición del conocimiento tienden a emplear menos estas estrategias.

Discusión y conclusión. Los hallazgos de este estudio informan a los educadores sobre la necesidad de promover las creencias epistemológicas de los adolescentes para cada tema (por ejemplo, ciencias, artes del lenguaje) como un método para facilitar su motivación y aprendizaje autorregulado. Recomendamos que la investigación futura debería incluir evaluaciones de las orientaciones culturales de los participantes o la especificidad del dominio de las creencias epistemológicas, que pueden variar las asociaciones de las creencias con el aprendizaje autorregulado. Además, la investigación futura puede seguir investigando otros mediadores potenciales de la relación entre las creencias epistemológicas y el aprendizaje autorregulado.

Palabras clave: Creencias epistemológicas, Estrategias de aprendizaje autorreguladas, Modelo de ruta de grupos múltiples, Estudiantes de secundaria. 


\section{Introduction}

The seminal work of Perry (1970) postulates that the process of epistemological development is a sequence of three stages in which one's notion of what knowledge consists of is progressively isolated, differentiated, and reintegrated into increasingly complex concepts. Perry's scheme of moral and intellectual development further demonstrates three successive epistemological positions, namely dualism, multiplicity, and relativism. In the stage of dualism, students believe that authorities unquestioningly separate right from wrong, whereas in the stage of multiplicity students believe that information is neither absolute nor externally controlled. In the third stage of relativism, opinions are evaluated based on context and evidence. Based on Perry's initial work, various frameworks of epistemological beliefs have been developed (for example, see review by Hofer \& Pintrich, 1997).

Prior research consistently provides evidence supporting potential relationships between epistemological beliefs and learning (e.g. Dweck \& Leggett, 1988; Law, Chan, \& Sachs, 2008; Schommer, Grouse, \& Rhodes, 1992). For instance, students tend to encounter more difficulty comprehending information in complex domains such as medicine and statistics when they believe that knowledge is characterized as isolated facts (Schommer, Grouse, $\&$ Rhodes, 1992). Students are also more likely to display helpless behavior when presented with academically challenging tasks if they believe that the ability to learn is genetically determined (Dweck \& Leggett, 1988). The study by Law, Chan, and Sachs (2008) with 417 Chinese elementary school children found that higher achievers outperformed lower achievers on beliefs, strategy, and comprehension achievement, with the greatest contribution from constructivist beliefs of learning. Additionally, Choi \& Park (2013) investigated among middle school students in South Korea the relationship between the epistemological beliefs and selfdirectedness in learning, and found that all aspects of epistemological beliefs associated with self-directedness. More recently, research (Özgen et al, 2019) showed a predictive relationship between the epistemogical beliefs and attitudes toward mathematical problem solving in middle school students.

Kizilgunes, Tekkaya, and Sungur's (2009) proposed a model, which assumed that epistemological beliefs influence achievement indirectly through their effect on achievement motivation and learning approach. Their findings, based on a sample of $6^{\text {th }}$ grade Turkish elementary school students, suggested that students who believed knowledge to be evolving 
(i.e., development) and handed down by authority (i.e., source) were more likely to be selfefficacious regarding their learning and based on a higher extent of learning and performancegoal orientations. More "sophisticated" epistemological beliefs tended to be associated with a higher level of self-reported monitoring strategies (Bromme, Pieschl, \& Stahl, 2010; Muis, 2007). Evidence indicates that beliefs about the nature of knowledge and knowing are related to learners' cognitive strategy use and academic performance (Hofer \& Pintrich, 1997; Schommer, 1990).

Specifically, the five epistemic beliefs described by Schommer (1990) are certain knowledge (i.e., absolute knowledge exists); simple knowledge (i.e., knowledge consists of discrete facts); omniscient authority (i.e., authorities can access inaccessible knowledge); quick learning (i.e., learning occurs in a rapid fashion), and innate ability (i.e., the level of ability to acquire knowledge is endowed at birth) (Schraw et al., 2002). There is a broad spectrum of perspectives on defining self-monitoring and self-regulated learning. Acknowledging the complexity of self-regulating learning, Zimmerman (2000) argued that self-regulation is not just a mental ability or a skill of academic performance, but rather a process of selfdirecting in which students transform their ability to perform academic tasks. Further, according to Zimmerman, self-regulation can refer to goal attaining thoughts, emotions, and behaviors generated by the students. Pintrich and De Groot (1990) noted the impacts on classroom performance by learners' metacognitive and actual cognitive strategies and their management and control of these strategies and effort on learning tasks. They developed the Motivational Strategies for Learning Questionnaire (MLSQ) to capture five motivation and self-regulatory (cognitive-metacognitive) components to test their hypothesis. Pintrinch (1999) defined selfregulated learning as an active process in which learners strategize to control their motivation, cognition, and behaviors for learning activities.

\section{Purpose and Research Questions}

Though epistemological beliefs have been hypothesized to be important covariates with several motivational and learning constructs, empirical evidence among early adolescents, especially cross-culturally, is lacking. The purpose of the current study is to examine the relationship between epistemological beliefs, academic motivation, and self-regulated learning strategies among different ethnic groups of American adolescents. 
Based on Schommer's framework of five epistemological beliefs (Schraw, Bendixen, \& Dunkle, 2002) and the constructs of self-regulation proposed by Pintrich and De Groot (1990), controlling for parental education level and self- reported grade point average, the current study attempts to address the following three research questions:

1) Is there a relationship between epistemological beliefs and motivation?

2) Is there a relationship between epistemological beliefs and self-regulatory learning strategies?

3 Are there differences in the relationships of epistemological beliefs and selfregulatory learning strategies between Latino and Asian American adolescents?

\section{Method}

This quantitative study utilized a correlational design to examine the relationship between epistemological beliefs and self-regulated learning strategies in adolescents attending middle schools.

\section{Participants}

A total of 364 middle school students ( $6^{\text {th }}$ to $8^{\text {th }}$ grade) from Southern California public middle schools participated. The sample consisted of 139 (38.2\%) Latino, 145 Asian (39.8\%), and $80(22 \%)$ students from other ethnic groups, with $219(60.2 \%)$ identifying themselves as female and $145(39.8 \%)$ as male. Forty-one (11.3\%) students had parents with less than a high school education, 26 (7.1\%) students had parents with some high school education, 55 (15.1\%) students had parents with some college, 95 (26.1\%) students had parents with college level education, 71 (19.5\%) students had parents with master's level education, and 27 (7.4\%) students had parents with doctoral level education.

\section{Data collection Procedures}

Although the study focused on Latino and Asian American adolescents, the two dominant student groups in number in the population of Southern California, all students in the science classes were invited to participate in the study. After obtaining the Institutional Review Board (IRB) approval, parent consent forms, and student assent forms were sent to students invited to participate in the study. A questionnaire composed of a battery of scales, described in the next section, was administered before or after a science class session only to the students who signed the assent form and with parental permission. 


\section{Instruments}

The demographic portion of the instrumentation collected student information on gender, ethnicity, grade level, highest parental education level, and student self-reported grade point average (GPA). To serve the purpose of the study and to address the research questions, the instrumentation included the two other research components. The two additional components included are the questions on epistemological beliefs, academic motivation, and selfregulated learning strategies.

Epistemological beliefs. The students' epistemological beliefs were measured with 28 questions in the Epistemic Belief Inventory (EPI) developed by Schraw et al. (2002). Using varimax rotation, exploratory factor analysis yielded nine constructs with eigenvalues greater than one, explaining fifty-nine percent of the variance. However, similar to the findings by Schraw et al. (2002), only fifteen questions (although not the exact same questions) clustered with interpretable factors consistent with Schommer (1990)'s framework of five epistemological beliefs (quick learning, simple knowledge, innate ability, omniscient knowledge, and certain knowledge). Table 1 displays factor names, item to factor loadings, eigenvalues and Cronbach's coefficient $\alpha$ for the present study.

Table 1. Factor Structure of the Epistemological Belief Inventory

Factor

Item

Loading

Factor 1: Quick Learning (Eigenvalue $=3.56, \alpha=.72$ )

15. If you do not learn something quickly, you will not ever learn it.

27. Working on a problem with no quick solution is a waste of time.

20. If you have not understood a chapter the first time through, going back over it will not help.

Factor 2: Certain Knowledge (Eigenvalue $=2.27, \alpha=.53$ )

23. What is true today will be true tomorrow.

4. People should always obey the law.

1. Most things worth knowing are easy to understand.

7. Parents should teach their children all there is to know about life. 
Item

Factor 3: Simple Knowledge (Eigenvalue $=2.02, \alpha=.52$ )

17. Things are simpler than most professors would have you believe.

11. The best ideas are often the most simple.

12. Instructors should focus on facts instead of theories.

\section{Factor 4: Innate Ability (Eigenvalue $=1.72, \alpha=.43$ )}

16. Some people just have a knack for learning and other do not.

13. Some people are born with special gifts and talents.

3. Students who learn things quickly are the most successful.

\section{Factor 5: Omniscient Knowledge (Eigenvalue $=1.49, \alpha=.48$ )}

25 . When someone in authority tells me what to do, I usually do it.

26. People should not question authority.

Academic motivation and self-regulated learning strategies. Students' academic motivation and self-regulated learning strategies were measured by the forty-four questions from Motivated Strategies for Learning Questionnaire (Pintrich \& DeGroot, 1990), which was designed to measure three motivational components (self-efficacy, intrinsic value, and test anxiety) and two self-regulated learning components (cognitive strategy use and self-regulation). Self-efficacy $(\alpha=.87)$, consisted of nine questions, intrinsic value $(\alpha=.83)$ also consisted of nine questions, while test anxiety ( $\alpha=.79)$ consisted of four questions. Cognitive strategy use ( $\alpha=.81)$ consisted of thirteen questions, and self-regulation $(\alpha=.74)$ consisted of nine questions.

\section{Data Analysis}

We first employed bivariate correlations and multiple regressions to explore the relationship between epistemogical beliefs and self-regulated learning strategies focusing on comparing Latino and Asian American adolescents. Next, we performed a single group path analysis to include all participants to examine the relationships between epistemological beliefs and self-regulated learning strategies, while controlling parental education level and GPA. Finally, we conducted multiple group path analysis to compare the relationships between epistemological beliefs and self-regulated learning strategies across ethnic groups, while major focus was placed on Latino and Asian American adolescents. 


\section{Results}

\section{Bivariate Correlations}

Bivariate correlations among all the research variables were separately estimated for Latino American Adolescents and Asian American adolescents. Table 2 displays intercorrelations for parent education level, GPA, epistemological beliefs and self-regulated learning strategies for Latino American adolescents.

Table 2. Intercorrelations for Epistemological Beliefs and Self-Regulated Learning Strategies for Latino American Students

\begin{tabular}{|c|c|c|c|c|c|c|c|c|c|c|c|}
\hline Scales & 1 & 2 & 3 & 4 & 5 & 6 & 7 & 8 & 9 & 10 & 11 \\
\hline \multicolumn{12}{|l|}{ 1. Parent education level } \\
\hline 2. GPA & .03 & & & & & & & & & & \\
\hline 3. Quick learning & $-.22 * *$ & $-.26^{* *}$ & & & & & & & & & \\
\hline 4. Simple knowledge & -.11 & -.05 & $.19 *$ & & & & & & & & \\
\hline 5. Innate ability & $-.19 * *$ & -.05 & $.25^{* *}$ & $.38^{* *}$ & & & & & & & \\
\hline 6. Omniscient knowledge & -.14 & .01 & $.17 *$ & .15 & .15 & & & & & & \\
\hline 7. Certain knowledge & -.10 & .06 & .04 & $.25 * *$ & $.30 * *$ & $.37 * *$ & & & & & \\
\hline 8. Self-efficacy & -.03 & $.26^{* *}$ & -.04 & .15 & .14 & $.34 * *$ & $.45^{* *}$ & & & & \\
\hline 9. Intrinsic value & .01 & .08 & -.04 & $.19^{*}$ & $.22 *$ & $.26^{* *}$ & $.50^{* *}$ & $.67 * *$ & & & \\
\hline 10. Test anxiety & -.07 & $-.18 *$ & $.27 * *$ & $.41 * *$ & $.38 * *$ & .03 & .07 & $-.17 *$ & -.09 & & \\
\hline 11. Cognitive strategy use & -.02 & .16 & .04 & $.17 *$ & .17 & $.24 * *$ & $.49^{* *}$ & $.58 * *$ & $.72 * *$ & -.06 & \\
\hline 12. Self-regulation & -.001 & .12 & .05 & .06 & $.17 *$ & $.35^{* *}$ & $.40 * *$ & $.62 * *$ & $.63^{* *}$ & $-.23 * *$ & $.73 * *$ \\
\hline
\end{tabular}

$* * p<.01, * p<.05$.

For Latino American students, it is worthy of noting that simple knowledge is positivity correlated with innate ability $(\mathrm{r}=.38, \mathrm{p}<.01)$, and test anxiety $(r=.41, p<.01)$. Innate ability is positively correlated with certain knowledge $(r=.30, p<.01)$, and test anxiety $(r=.41, p<.01)$. Omniscient knowledge is positively correlated with certain knowledge $(r=.37, p<.01)$, self- 
efficacy $(r=.34, p<.01)$, and self-regulation $(r=.35, p<.01)$. Certain knowledge is positively correlated with self-efficacy $(r=.45, p<.01)$, intrinsic value $(r=.50, p<.01)$, cognitive strategy use $(r=.49, p<.01)$, and self-regulation $(r=.40, p<.01)$. Self-efficacy is positively correlated with intrinsic value $(\mathrm{r}=.67, \mathrm{p}<.01)$, cognitive strategy use $(r=.49, p<.01)$, and self-regulation $(r=.62, p<.01)$. Intrinsic value is positively correlated with cognitive strategy use $(r=.72$, $p<.01)$, and self-regulation $(r=.63, p<.01)$. Lastly, cognitive strategy use is positively correlated with self-regulation $(r=.73, p<.01)$.

The results for the Asian American adolescents are reported in Table 3. It is worthy of noting that GPA is negatively correlated with quick learning ( $\mathrm{r}=-.33 \cdot \mathrm{p}<.01)$, while positively correlated with self-efficacy $(\mathrm{r}=.32, \mathrm{p}<.01)$. Quick learning is positively correlated with test anxiety $(\mathrm{r}=.34, \mathrm{p}<.01)$. Omniscient knowledge is positively correlated with certain knowledge $(\mathrm{r}=.42, \mathrm{p}<.01)$, intrinsic value $(\mathrm{r}=.31, \mathrm{p}<.01)$, and cognitive strategy use $(\mathrm{r}=.31, \mathrm{p}<.01)$.

Table 3. Intercorrelations for Epistemological Beliefs and Self-Regulated Learning Strategies for Asian American Students

\begin{tabular}{|c|c|c|c|c|c|c|c|c|c|c|c|}
\hline Scales & 1 & 2 & 3 & 4 & 5 & 6 & 7 & 8 & 9 & 10 & 11 \\
\hline \multicolumn{12}{|l|}{ 1. Parent education level } \\
\hline 2. GPA & -.02 & & & & & & & & & & \\
\hline 3. Quick learning & $-.22 *$ & $-.33 * *$ & & & & & & & & & \\
\hline 4. Simple knowledge & .03 & -.04 & .15 & & & & & & & & \\
\hline 5. Innate ability & .05 & $.20 *$ & .09 & .04 & & & & & & & \\
\hline 6. Omniscient knowledge & .15 & .04 & .08 & .06 & .10 & & & & & & \\
\hline 7. Certain knowledge & -.02 & $.19^{*}$ & $.21 *$ & .13 & $.22 * *$ & $.42 * *$ & & & & & \\
\hline 8. Self-efficacy & $.20 *$ & $.32 * *$ & $-.25 * *$ & .005 & .15 & $.23 * *$ & .12 & & & & \\
\hline 9. Intrinsic value & $.19 *$ & .12 & $-.20 *$ & -.04 & -.01 & $.31 * *$ & $.26 * *$ & $.53 * *$ & & & \\
\hline 10. Test anxiety & -.16 & -.14 & $.34 * *$ & .001 & .08 & -.023 & .13 & $-.43 * *$ & $-.20 *$ & & \\
\hline 11. Cognitive strategy use & .14 & .11 & -.14 & .09 & .13 & $.31 * *$ & $.29 * *$ & $.39 * *$ & $.61 * *$ & -.09 & \\
\hline 12. Self-regulation & .14 & $.24 * *$ & $-.29 * *$ & .01 & -.01 & $.27 * *$ & $.24 * *$ & $.51 * *$ & $.70 * *$ & $-.25 * *$ & $.73 * *$ \\
\hline
\end{tabular}

$* * p<.01, * p<.05$. 
Self-efficacy is positively correlated with intrinsic value $(r=.53, p<.01)$, cognitive strategy use $(\mathrm{r}=.39, \mathrm{p}<.01)$, and self-regulation $(\mathrm{r}=.51, \mathrm{p}<.01)$, while negatively correlated with text anxiety $(r=-.43, p<.01)$. Intrinsic value is positively correlated with cognitive use $(\mathrm{r}=.61, \mathrm{p}<.01)$, and self-regulation $(\mathrm{r}=.70, \mathrm{p}<.01)$. Finally, cognitive strategy use is positively correlated with self-regulation $(\mathrm{r}=.73, \mathrm{p}<.01)($ See Table 3).

\section{Multiple Regressions}

Separate multiple regressions were performed for Latino and Asian American adolescents to examine the relationship between epistemological beliefs and the self-regulated learning strategies. In order to control for parent education level and GPA, these two variables are included in the subsequent simultaneous regression models as predictors when reporting the findings.

Epistemological beliefs predicting self-efficacy. Omniscient knowledge $(\beta=.21, p$ $<.01)$ and certain knowledge $(\beta=.36, p<.001)$ positively predict self-efficacy for Latino American adolescents $\left(R^{2}=.30, F(7,130)=7.90, p<001\right)$; Omniscient knowledge $(\beta=.21, p<$ $.05)$ positively predicts self-efficacy for Asian American adolescents $\left(R^{2}=.21, F(7,132)=\right.$ $4.94, p<.001)$.

Epistemological beliefs predicting intrinsic-value. Certain knowledge $(\beta=.43, p<.001)$ positively predicts intrinsic value for Latino American adolescents $\left(R^{2}=.28, F(7,130)\right.$ $=7.278, p<.001)$. For Asian American adolescents, both omniscient knowledge $(\beta=.22, p<.05)$ and certain-knowledge $(\beta=.25, p<.05)$ positively predict intrinsic value, while quick learning $(\beta=-.22, p<.05)$ negatively predicts intrinsic value $\left(R^{2}=.20, F(7,132)=4.61, p<.001\right)$.

Epistemological beliefs predicting test-anxiety. Simple knowledge $(\beta=.31, p<.01)$ and innate-ability $(\beta=.25, p<.01)$ are positive predictors of test-anxiety for Latino American adolescents $\left(R^{2}=.27, F(7,130)=6.9, p<.001\right)$; Quick learning $(\beta=.28, p<.01)$ is a positive predictor of test anxiety for Asian American adolescents $\left(R^{2}=.14, F(7,132)=3.0, p<.01\right)$.

Epistemological beliefs predicting cognitive-strategy-use. Certain knowledge $(\beta=.45$, $p<.001)$ is a positive predictor of cognitive strategy use for Latino American adolescents $\left(R^{2}\right.$ $=.27, F(7,130)=6.696, p<001)$. For Asian American adolescents, both omniscient 
knowledge $(\beta=.21, p<.05)$ and certain knowledge $(\beta=.22, p<.05)$ positively predict cognitive strategy use, while quick learning negatively predicts cognitive strategy use $(\beta=-.22, p<.05)$, $\left(R^{2}=.18, F(7,132)=4.18, p<.001\right)$.

Epistemological beliefs predicting self-regulation. Both omniscient knowledge $(\beta$ $=.25, p<.01)$ and certain knowledge $(\beta=.30, p<.001)$ positively predict self-regulation for Latino American adolescents $\left(R^{2}=.23, F(7,130)=5.66, p<.001\right)$. Similarly for Asian American adolescents, both omniscient knowledge $(\beta=.20, p<.05)$ and certain knowledge $(\beta=.22$, $p<.05)$ positively predict self-regulation, but quick learning $(\beta=-.30, p<.001)$ negatively predicts self-regulation $\left(R^{2}=.23, F(7,132)=5.58, p<.001\right)$.

\section{Single Group Path Analysis}

A single group path analysis including all the participants $(n=364)$ was performed to test the relationship between the exogenous variables (parent education level, GPA, quick learning, simple knowledge, innate ability, omniscient knowledge, certain knowledge) and the endogenous variables (self-efficacy, intrinsic value, test anxiety, cognitive strategy use, and selfregulation). Figure 1 represents the single group path analysis with all significant paths coefficients, $\chi^{2}(22, n=364)=22.23, p=0.45, C F I=1.00, G F I=.99, A G F I=.964$, RMSEA $=.005$.

Parent education level ( $\beta=.23)$, GPA ( $\beta=.33)$, quick learning $(\beta=.14)$, innate ability $(\beta=.14)$, omniscient knowledge $(\beta=.13)$, and certain knowledge $(\beta=.26)$ have positive direct effects on self-efficacy. GPA has a negative effect $(\beta=-.10)$ on intrinsic value, while certain knowledge $(\beta=.24)$ and self-efficacy $(\beta=.59)$ have a positive effect on intrinsic value. Innate ability $(\beta=.16)$ and certain knowledge $(\beta=.24)$ have a positive effect on test anxiety, while GPA $(\beta=-.11)$ and self-efficacy $(\beta=-.34)$ have a negative effect on test anxiety. Innate ability $(\beta=.11)$, certain knowledge $(\beta=.19)$, self-efficacy $(\beta=.20)$, and intrinsic value $(\beta=.46)$ have a positive effect on cognitive strategy use while simple knowledge $(\beta=-.10)$ has a negative effect on cognitive strategy use. Omniscient knowledge ( $\beta=.08)$, self-efficacy $(\beta=.13)$, intrinsic value $(\beta=.46)$, and cognitive strategy use $(\beta=.55)$ have a positive effect on self-regulation, while test-anxiety $(\beta=-.20)$ has a negative effect on self-regulation.

It is worthy of noting that self-efficacy is observed to have a large standardized path coefficient to intrinsic value $(\beta=.59)$, as well as a large negative standardized path coefficient on test anxiety $(\beta=-.83)$. It is also observed that intrinsic value has a large standardized path 
coefficient to cognitive strategy use $(\beta=.46)$, and cognitive strategy use has a large standardized path coefficient to self-regulation $(\beta=.55)$.

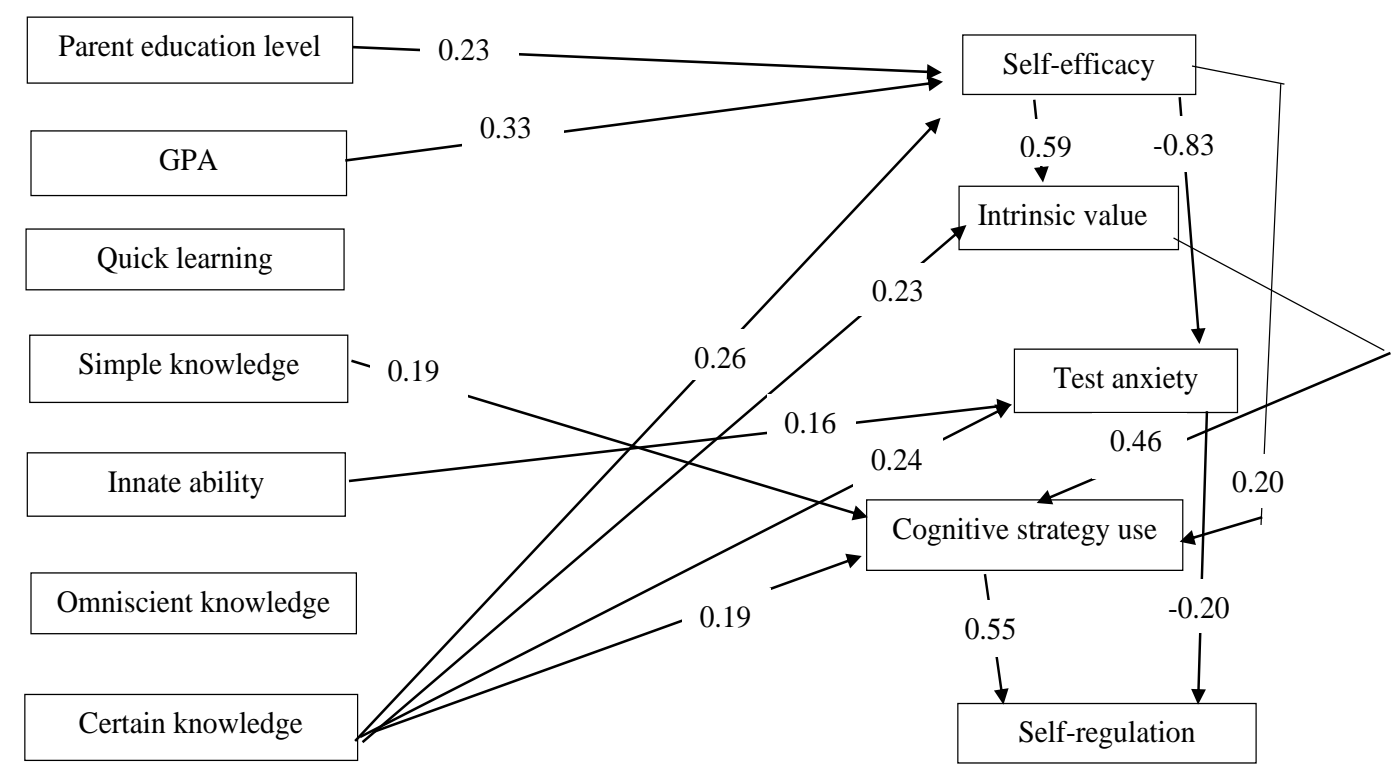

Figure 1. Path Diagram with Significant Coefficients for All Students in the Sample (Standard Path Coeffients with a Value Lower than 15 are Suppressed for Simplicity and Clarity)

\section{Multiple Group Path Model}

A multiple group path analysis is fitted with the primary purpose of testing for invariance with all the participants across the three student groups (Latino American, Asian American and all other) to further address the research questions. However, only the Latino American and Asian American students' results are the foci of the study and presented here due to the small sample sizes of the students of other ethnic background represented in the sample.

The primary parameters we wish to test for invariance included the causal paths that predict the five endogenous variables (self-efficacy, intrinsic value, test anxiety, cognitive strategy use, and self-regulation), along with the covariances among the seven exogenous variables (parent education level, GPA, quick learning, simple knowledge, innate ability, omniscient knowledge, and certain knowledge).

The study followed the standard practice of first testing the configural model with no constraints on the parameters across groups to test whether the proposed model fits the data 
well. Then, all of the regression paths and covariances were constrained to be equal across the three groups, and modification indices were checked to determine if the model fit could be substantially improved by freeing some of these constraints. A modification index exceeding the value of 3.84 suggests that the parameter in question may not be invariant across groups, though people typically round the number to 4.0 (Brown, 2015; Jaccard \& Wan, 1996). Setting 4.0 as the modification indices threshold for freeing constraints seems to identify the parameters, which vary across the groups in practically meaningful magnitudes. We then again reported on the fit of the model and presented results of parameter estimates.

\section{Multiple Group Path Model-Model Fit Results}

The proposed multiple group configural path model fit the data very closely, the maximum likelihood ratio $\chi^{2}(36, n=357)=26.74, p=0.869$. In addition, the comparative fit index (CFI) was equal to 1.00 and the Root Mean Square Error (RMSEA) was equal to 0.0. Since the proposed configural model fit the data well, we proceeded to constrain the regression paths and the covariances among the exogenous variables. After constraining for invariance the maximum likelihood ratio $\chi^{2}(102, n=357)=136.70, p=0.012$ and the RMSEA $(0.053)$ suggested that the fit could be improved by freeing some of the constraints. After examining the modification indices, we deemed that 23 of the 33 regression paths were invariant across the groups. This result implied that ten regression paths needed to be freed across the groups to improve the model fit.

The model fit for this final model also fit the data well. The maximum likelihood ratio was $\chi^{2}(82, n=357)=72.50, p=0.764$. The comparative fit index $(C F I)$ was equal to 1.00 and the RMSEA was equal to 0.0 .

\section{Multiple Group Path Model-Endogenous Effects on Self-Regulation}

The direct and indirect path relationships between the four endogenous predictors of self-regulation will be described in this section. Table 4 reports the direct and indirect effect estimates for the four endogenous variables on self-regulation and the relationships will be examined one variable at a time as displayed in Table 4. 
Table 4. Summary of Endogenous Effects on Self-Regulation

\begin{tabular}{lcccccc}
\hline & \multicolumn{2}{c}{ Latino } & & \multicolumn{2}{c}{ Asian } \\
\cline { 2 - 3 } \cline { 5 - 6 } Endogenous Predictors & Direct & Indirect & & Direct & Indirect \\
\hline Self-efficacy & $0.101^{*}$ & $0.197^{* *}$ & & $0.101^{*}$ & $0.214^{* *}$ \\
Intrinsic value & $0.162^{*}$ & $0.277^{* *}$ & & $0.274^{* *}$ & $0.243^{* *}$ \\
Cognitive strategy use & $0.515^{* *}$ & $\mathrm{NA}$ & & $0.470^{* *}$ & $\mathrm{NA}$ \\
Test anxiety & $-0.132^{* *}$ & $\mathrm{NA}$ & & $-0.132^{* *}$ & $\mathrm{NA}$ \\
\hline
\end{tabular}

$* * p<.01, * p<.05$.

Self-Efficacy. Self-efficacy displayed both positive direct effects and positive indirect effects on self-regulation. As the modification index value was less than 4.0, the direct effect of self-efficacy on self-regulation was 0.10 and did not vary across the subgroups. The magnitude of the indirect effects was larger than the direct effects and unlike the direct effects, the effect varied between Latino students and Asian students, with indirect effect stronger among Asian students.

Intrinsic Value. Both the direct and indirect effects of intrinsic value on self-regulation were statistically significant and varied across the student subgroups. The direct effect was the stronger for Asian students $(\beta=0.27)$ than for Latino students $(\beta=0.16)$. The indirect effect was stronger for Latino students than for Asian students.

Cognitive Strategy Use and Test Anxiety. Only direct effects on self-regulation were identified and diagrammed from cognitive strategy use and test anxiety. Cognitive strategy use had positive and significant direct effects on self-regulation for both ethnicity groups, with it being stronger for the Latino students $(\beta=0.52$ for Latinos and $\beta=0.47$ for Asian students). Test anxiety had a significant negative effect on self-regulation, the effects did not vary across groups, and the effect was negative $(\beta=-0.13)$.

\section{Multiple Group Path Model-Exogenous Effects on Self-Regulation}

Of the seven exogenous predictors of self-regulation, four had significant either direct or indirect effects. The four exogenous covariates with significant effects on self-regulation were certain knowledge, omniscient knowledge, quick learning and simple knowledge and are described below and shown in Table 5 . 
Table 5. Summary of Exogenous Effects on Self-Regulation

\begin{tabular}{lccllll}
\hline & \multicolumn{2}{c}{ Latino } & & \multicolumn{2}{c}{ Asian } \\
\cline { 2 - 3 } \cline { 5 - 6 } Exogenous Predictors & Direct & Indirect & & Direct & Indirect \\
\hline Certain knowledge & 0.033 & $0.267^{* *}$ & & 0.033 & $0.175^{* *}$ \\
Omniscient knowledge & $0.086^{*}$ & $0.081^{* *}$ & & $0.086^{*}$ & $0.089^{* *}$ \\
Quick learning & 0.076 & $-0.087^{*}$ & & $-0.101^{*}$ & $-0.154^{*}$ \\
Simple knowledge & $-0.068^{*}$ & -0.006 & & $-0.068^{*}$ & 0.044 \\
\hline
\end{tabular}

$* * p<.01, * p<.05$.

Certain Knowledge. Certain knowledge did not have significant direct effects on selfregulation, but it did have significant and positive indirect effects for both groups. The magnitude of the indirect effects was strongest for Latino students as compared to Asian students.

Omniscient Knowledge. Omniscient knowledge displayed small but significant positive effects on self-regulation directly and indirectly. The indirect effects were mediated mostly through self-efficacy.

Quick Learning. The direct effects of quick learning on self-regulation varied across the three groups. Latino students had a non-significant positive direct effect estimate while Asian students had a negative and borderline significant $(p=0.05)$ direct effect estimate. The combined indirect effects of quick learning were negative, small and significant for Latino and Asian Students and tended to be mediated through intrinsic value and test anxiety.

Simple Knowledge. Simple knowledge exhibited small negative direct effects on selfregulation, which did not vary across groups. There were no significant indirect effects for simple knowledge.

\section{Multiple Group Path Model-All Direct Effects That Vary Across Groups}

We present all the direct but varying path estimates for Latino and Asian students in Table 6. The direct effects on self-regulation have been previously discussed. The effect of 
intrinsic value on cognitive strategy use was significant for both Latino and Asian students, and the effect sizes were similar. Likewise, the effect of self-efficacy on intrinsic value was also significant and similar for Latino and Asian students. The effect of simple knowledge on test anxiety and certain knowledge on self-efficacy varied for the two groups of students. Both effects were present for Latino students and not present for Asian students.

Table 6. List of Varying Direct Paths across Ethnicity

\begin{tabular}{lcc}
\hline \multicolumn{1}{c}{ Direct Paths } & Latino & Asian \\
\hline Endogenous Variable: Self-regulation & & \\
Intrinsic value & $0.162^{*}$ & $0.274^{*}$ \\
Cognitive strategy use & $0.515^{*}$ & $0.470^{*}$ \\
Endogenous Variable: Cognitive strategy use & & \\
Intrinsic Value & $0.548^{*}$ & $0.509^{*}$ \\
Endogenous Variable: Text anxiety & & \\
Simple knowledge & $0.354^{*}$ & -0.040 \\
Endogenous Variable: Intrinsic value & & \\
Self-efficacy & $0.562^{*}$ & $0.519^{*}$ \\
Endogenous Variable: Self-efficacy & & \\
Certain knowledge & $0.338^{*}$ & -0.001 \\
Grade point average & $0.205^{*}$ & $0.249^{*}$ \\
\hline
\end{tabular}

$* * p<.01, * p<.05$.

Tables 7 and 8 have all the direct path estimates that are statistically significant for the Latino and Asian groups of students. Figures 2 and 3 are the diagrams of our final path model along with the significant parameter estimates for Latino American and Asian American students. As guided by the earlier testing of whether the path varied across the groups, the majority of the path coefficients were restrained as they didn't vary across the groups in practically meaningful magnitudes. 


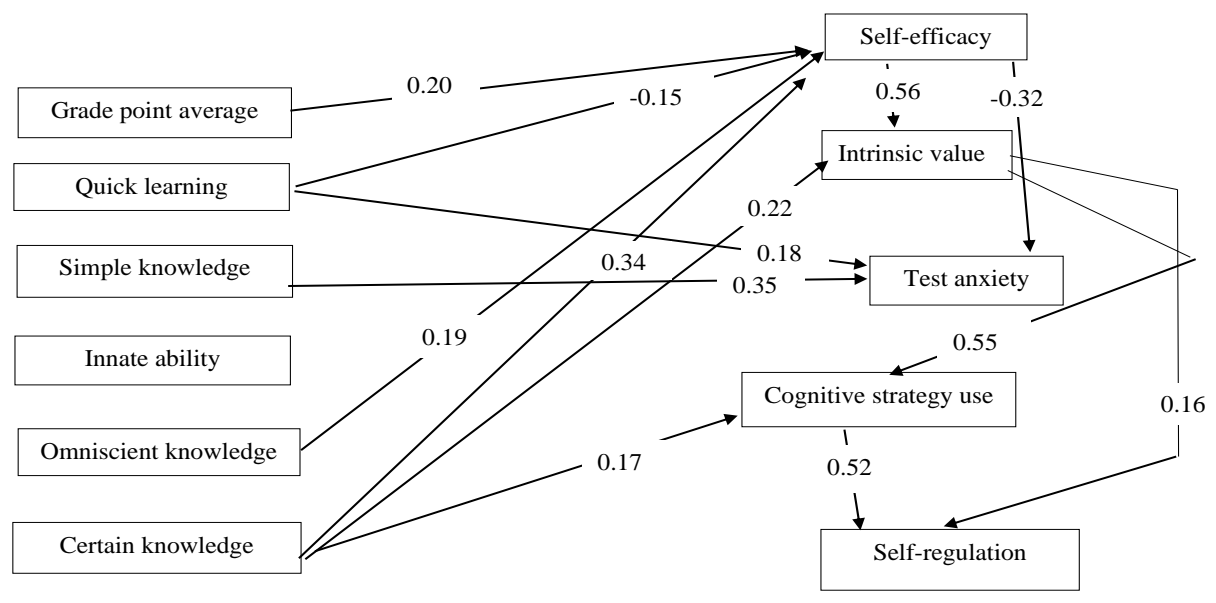

Figure 2. Path Diagram with All the Significant Coefficients for Latino American Students (Standard Path Coeffients with a Value Lower than .15 are Suppressed for Simplicity and Clarity)

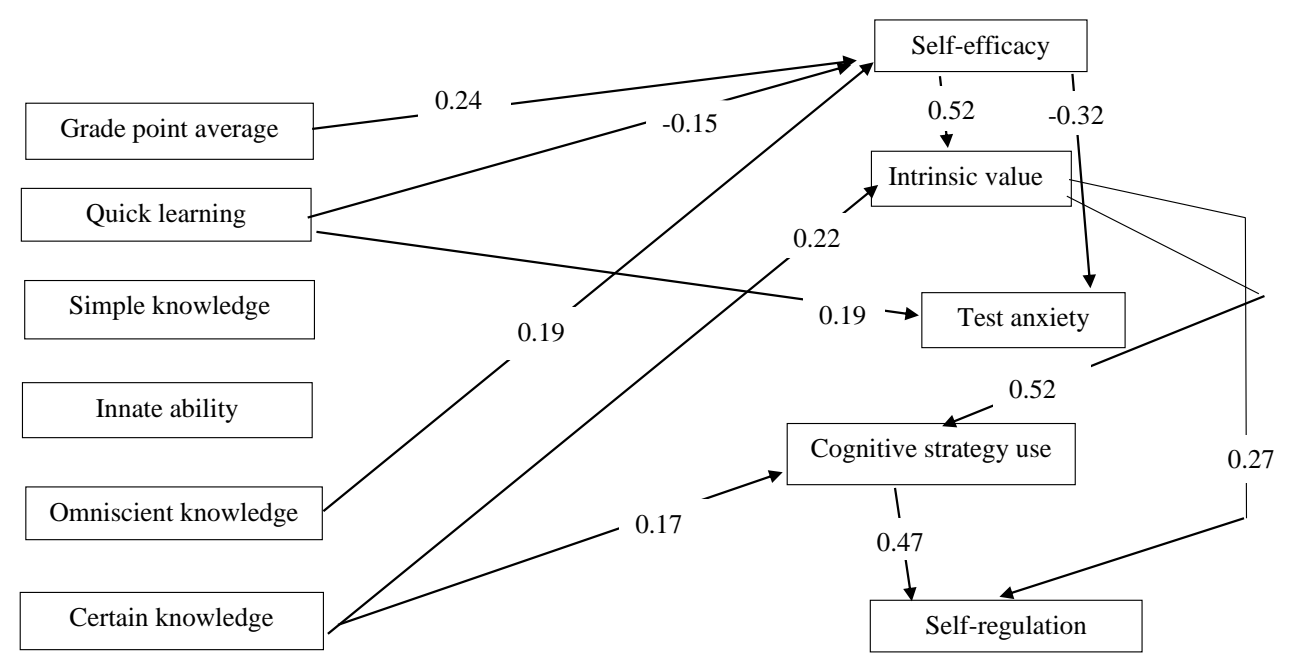

Figure 3. Path Diagram with All the Significant Coefficients for Asian American Students (Path Coeffients with a Value Lower than .15 are Suppressed for Simplicity and Clarity) 
Table 7. Direct Path Estimates for Latino American Students

\begin{tabular}{|c|c|c|c|c|}
\hline Constructs & Estimate & Std.Err & Z-value & $\mathbf{P}(>|\mathbf{z}|)$ \\
\hline \multicolumn{5}{|l|}{ Self-regulation } \\
\hline Self-efficacy & 0.101 & 0.043 & 2.332 & 0.020 \\
\hline Intrinsic value & 0.162 & 0.077 & 2.096 & 0.036 \\
\hline Test anxiety & -0.132 & 0.034 & -3.910 & 0.000 \\
\hline Cognitive strategy use & 0.515 & 0.075 & 6.869 & 0.000 \\
\hline Quick learning & 0.076 & 0.054 & 1.392 & 0.164 \\
\hline Simple knowledge & -0.068 & 0.033 & -2.076 & 0.038 \\
\hline Omniscient knowledge & 0.086 & 0.034 & 2.563 & 0.010 \\
\hline Certain knowledge & 0.033 & 0.037 & 0.879 & 0.379 \\
\hline \multicolumn{5}{|l|}{ Cognitive strategy use } \\
\hline Self-efficacy & 0.102 & 0.080 & 1.281 & 0.200 \\
\hline Intrinsic value & 0.548 & 0.078 & 7.001 & 0.000 \\
\hline Quick learning & 0.075 & 0.060 & 1.255 & 0.210 \\
\hline Simple knowledge & 0.055 & 0.039 & 1.439 & 0.150 \\
\hline Certain knowledge & 0.168 & 0.043 & 3.876 & 0.000 \\
\hline Grade point average & 0.096 & 0.061 & 1.574 & 0.116 \\
\hline \multicolumn{5}{|l|}{ Test anxiety } \\
\hline Self-efficacy & -0.323 & 0.061 & -5.325 & 0.000 \\
\hline Intrinsic value & 0.010 & 0.062 & 0.157 & 0.875 \\
\hline Quick learning & 0.186 & 0.049 & 3.767 & 0.000 \\
\hline Simple knowledge & 0.354 & 0.075 & 4.727 & 0.000 \\
\hline Innate ability & 0.127 & 0.051 & 2.487 & 0.013 \\
\hline Certain knowledge & 0.084 & 0.053 & 1.581 & 0.114 \\
\hline \multicolumn{5}{|l|}{ Intrinsic value } \\
\hline Self-efficacy & 0.562 & 0.066 & 8.539 & 0.000 \\
\hline Quick learning & -0.108 & 0.042 & -2.564 & 0.101 \\
\hline Innate ability & 0.090 & 0.062 & 1.441 & 0.150 \\
\hline Omniscient knowledge & 0.056 & 0.041 & 1.376 & 0.169 \\
\hline Certain knowledge & 0.216 & 0.044 & 4.909 & 0.000 \\
\hline Grade point average & -0.101 & 0.063 & -1.602 & 0.109 \\
\hline \multicolumn{5}{|l|}{ Self-Efficacy } \\
\hline Parent education level & 0.016 & 0.074 & 0.211 & 0.833 \\
\hline Quick learning & -0.150 & 0.051 & -2.939 & 0.003 \\
\hline Simple knowledge & 0.034 & 0.048 & 0.713 & 0.476 \\
\hline Innate ability & 0.099 & 0.049 & 2.007 & 0.045 \\
\hline Omniscient knowledge & 0.186 & 0.049 & 3.826 & 0.000 \\
\hline Certain knowledge & 0.338 & 0.076 & 4.427 & 0.000 \\
\hline Grade point average & 0.206 & 0.073 & 2.799 & 0.005 \\
\hline
\end{tabular}


Table 8. Direct Path Estimates for Asian American Students

\begin{tabular}{|c|c|c|c|c|}
\hline Constructs & Estimate & Std.Err & Z-value & $\mathbf{P}(>|\mathbf{z}|)$ \\
\hline \multicolumn{5}{|l|}{ Self-regulation } \\
\hline Self-efficacy & 0.101 & 0.043 & 2.332 & 0.020 \\
\hline Intrinsic value & 0.274 & 0.066 & 4.152 & 0.000 \\
\hline Test anxiety & -0.132 & 0.034 & -3.910 & 0.000 \\
\hline Cognitive strategy use & 0.470 & 0.063 & 7.472 & 0.000 \\
\hline Quick learning & -0.101 & 0.052 & -1.951 & 0.051 \\
\hline Simple knowledge & -0.068 & 0.033 & -2.076 & 0.038 \\
\hline Omniscient knowledge & 0.086 & 0.034 & 2.563 & 0.010 \\
\hline Certain knowledge & 0.033 & 0.037 & 0.879 & 0.379 \\
\hline \multicolumn{5}{|l|}{ Cognitive strategy use } \\
\hline Self-efficacy & 0.090 & 0.082 & 1.102 & 0.271 \\
\hline Intrinsic value & 0.509 & 0.080 & 6.391 & 0.000 \\
\hline Quick learning & -0.074 & 0.071 & -1.041 & 0.298 \\
\hline Simple knowledge & 0.055 & 0.039 & 1.439 & 0.150 \\
\hline Certain knowledge & 0.168 & 0.043 & 3.876 & 0.000 \\
\hline Grade point average & -0.034 & 0.073 & -0.465 & 0.642 \\
\hline \multicolumn{5}{|l|}{ Test anxiety } \\
\hline Self-efficacy & -0.323 & 0.061 & -5.325 & 0.000 \\
\hline Intrinsic value & 0.010 & 0.062 & 0.157 & 0.875 \\
\hline Quick learning & 0.186 & 0.049 & 3.767 & 0.000 \\
\hline Simple knowledge & -0.040 & 0.074 & -0.549 & 0.583 \\
\hline Innate ability & 0.127 & 0.051 & 2.487 & 0.013 \\
\hline Certain knowledge & 0.084 & 0.053 & 1.581 & 0.114 \\
\hline \multicolumn{5}{|l|}{ Intrinsic value } \\
\hline Self-efficacy & 0.519 & 0.073 & 7.154 & 0.000 \\
\hline Quick learning & -0.108 & 0.042 & -2.564 & 0.010 \\
\hline Innate ability & -0.110 & 0.070 & -1.577 & 0.115 \\
\hline Omniscient knowledge & 0.056 & 0.041 & 1.376 & 0.169 \\
\hline Certain knowledge & 0.216 & 0.044 & 4.909 & 0.000 \\
\hline \multirow{2}{*}{\multicolumn{5}{|c|}{ Self-Efficacy }} \\
\hline & & & & \\
\hline Parent education level & 0.136 & 0.077 & 1.774 & 0.076 \\
\hline Quick learning & -0.150 & 0.051 & -2.939 & 0.003 \\
\hline Simple knowledge & 0.034 & 0.048 & 0.713 & 0.476 \\
\hline Innate ability & 0.099 & 0.049 & 2.007 & 0.045 \\
\hline Omniscient knowledge & 0.186 & 0.049 & 3.826 & 0.000 \\
\hline Certain knowledge & -0.001 & 0.081 & -0.012 & 0.991 \\
\hline Grade point average & 0.249 & 0.080 & 3.114 & 0.002 \\
\hline
\end{tabular}

\section{Discussion and conclusion}

This study contributes to the demonstration of the predicting role of each aspect of epistemological beliefs on the components of academic motivation and self-regulatory learning strategies among learners in early and mid-adolescence. In general, the findings about the relationship between epistemological beliefs and the use of self-regulatory strategies are consistent with prior research (e.g., Barnard, Lan, Crooks, \& Paton, 2008; Savoji, Niusha, \& Boreiri, 2013; Stromso \& Bates, 2010). Specifically, certain knowledge, omniscient 
knowledge and innate ability beliefs about the nature of knowledge predicts positive relationships with self-efficacy and intrinsic value components of motivation. Quick learning and simple knowledge beliefs predict negative relationships with self-efficacy and intrinsic value but positive relationship with test anxiety.

Similarly, in the aspect of self-regulatory learning strategies, those who believe in the absolute nature of knowledge and the authoritative nature of knowledge tend to use cognitive and self-regulatory learning strategies more often, while those who believe in the speed of knowledge acquisition tend to employ those strategies less. The consistency of certain knowledge and omniscient authority beliefs as predictors of the essential components of academic motivation and self-regulatory learning strategies supports previous research findings that more complex beliefs of the nature of knowledge generate more sophisticated beliefs in learning (Law et al., 2008). Moreover, epistemological beliefs play an important role of setting the use of cognitive and self-regulatory strategies (such as rehearsal, organization, critical thinking, and metacognition) to monitor the learning process (Winne \& Hadwin, 1998).

The quick learning and simple knowledge beliefs, however, constrain academic motivation or self-regulation. With the lack of understanding of the structure of knowledge, lack of effort and intrinsic interest in learning, test anxiety becomes a hindrance to the learners. The path analyses further indicate that overall, certain knowledge and omniscient knowledge are related to self-regulation in learning directly or indirectly through the mediators of selfefficacy or intrinsic motivation.

Another contribution of this study is the revelation of some patterns in the findings among the ethnic groups. For instance, for the Latino students, certain knowledge is positively related to self-efficacy, and simple knowledge is positively related with test anxiety. And these two relationships did not emerge for Asian students. Thus, cultural conceptualizations of the nature of knowledge and learning may guide the learners' motivation and learning strategies in differing ways.

Despite the contributions, there are several limitations of the current study. One limitation is the measurement of epistemological beliefs. Although the exploratory factor analysis of the revealed five interpretable factors of EPI (Schraw et al, 2002), only the factor of quick learning $(\alpha=.72)$, the factor of certain knowledge $(\alpha=.53)$ and the factor of simple knowledge 
( $\alpha=$. 52) exhibited acceptable or minimal levels of reliability. The factors of innate ability $(\alpha=.43)$ and omniscient knowledge $(\alpha=.48)$ demonstrated questionable levels of reliability. The variables are used as predictors both in regression and path models. We recommend cautious generalizations of the findings especially with the factor of innate ability and omniscient knowledge. Further studies on the measures these epistemological beliefs are strongly encouraged. Another limitation is relatively small sample size. We recommend an increase sample size to increase statistical power to more adequately investigate these important relationships.

Findings from this study inform educators of the need to advance adolescents' epistemological beliefs for each subject (e.g., science, language arts) as a method to facilitate their motivation and self-regulated learning (e.g., Kienhues, Bromme, \& Stahl, 2008). One recent study (Atasoy \& Küçük, 2020) showed the potential that the epistemological beliefs can be developed though writing to learn activities in eighth graders. Belland et al (2020) also demonstrated that engaging middle school students in problem-based learning can influence students' epistemological beliefs.

The current study did not include assessments of the participants' cultural orientations, or the domain specificity of the epistemological beliefs, which may vary the associations of the beliefs with self-regulated learning (Pintrich \& Zusho, 2002). Future studies can further investigate other mediators of the relationship between epistemological beliefs and selfregulatory learning as well the domain specificity of the epistemological beliefs and the possible relationship with students' self-identified cultural orientations.

\section{References}

Atasoy, S., \& Küçük, O. (2020). Development of Eighth Grade Students' Epistemological Beliefs through Writing-to-Learn Activities. Journal of Science Learning, 3(2), 57-66.

Barnard, L., Lan, W.Y., Crooks, M. S., \& Paton, O.V. (2008). The relationship between epistemological beliefs and self-regulated learning skills in the online course environment. Journal of Online Learning and Teaching, 4(3), 261-266.

Belland, B. R., Gu, J., Kim, N. J., Jaden Turner, D., \& Mark Weiss, D. (2019). Exploring epistemological approaches and beliefs of middle school students in problem-based learning. The Journal of Educational Research, 112(6), 643-655. https://doi.org/10.1080/00220671.2019.1650701 
Bromme, R., Pieschl, S., \& Stahl E. (2010). Epistemological beliefs are standards for adaptive learning: a functional theory about epistemological beliefs and metacognition. Metacognition Learning, 5, 5-26.

Brown, T. A. (2015). Confirmatory factor analysis for applied research. The Guilford Press: New York.

Choi, J., \& Park, E. A. (2013). Epistemological Beliefs and Self-Directedness in Learning of South Korean Middle School Students. Asia-Pacific Education Researcher, 22(4), $541-548$.

Dweck, C. S., \& Leggett, E. L. (1988). A social-cognitive approach to motivation and personality. Psychological Review, 95(2), 256-273.

Hofer, B. K., \& Pintrich, P. R. (1997). The development of epistemological theories: Beliefs about knowledge and knowing and their relation to learning. Review of Educational Research, 67, 88-140.

Jaccard, J. J., \& Wan, C. K. (1996). LISREL approaches to interaction effects in multiple regression. Sage Publications

Kienhues, D., Bromme, R., \& Stahl, E. (2008). Changing epistemological beliefs: The unexpected impact of a short-term intervention. British Journal of Educational Psychology, $78,545-565$.

Kizilgunes, B., Tekkaya, C., \& Sungur, S. (2009). Modeling the relations, among students' epistemological beliefs, motivation, learning approach, and achievement. The Journal of Educational Research, 102(4), 243-255.

Law, Y., Chan, C. K. K., \& Sachs, J. (2008). Beliefs about learning, self-regulated strategies and text comprehension among Chinese children. British Journal of Educational Psychology, 78, 51-73.

Li, J. (2012). Cultural foundations of learning: East and west. Cambridge University Press.

Muis, K. R., (2007). The role of epistemic beliefs in self-regulated learning. Educational Psychologist, 42(3), 173-190.

Özgen, K., Aydin, M., Dinç, R., Seker, I., \& Alkan, Y. (2019). The Investigation of Middle School Students' Epistemological Beliefs and Their Attitudes toward Problem Solving: The Sample of Rural Area. Acta Didactica Napocensia, 12(1), 141-152.

Perry, W. G. Jr. (1970). Forms of intellectual and ethical development in the college years. Academic Press.

Pintrich, P. R. (1999). The role of motivation in promoting and sustaining self-regulated learning. International Journal of Educational Research, 31(6), 459-470. 
Pintrich, R. R., \& DeGroot, E. V. (1990). Motivational and self-regulated learning components of classroom academic performance. Journal of Educational Psychology, 82, $33-40$.

Pintrich, R. R., \& Zusho, A. (2002). The development of academic self-regulation: The role of cognitive and motivational factors. In A. Wigfield \& J. S. Eccles (Eds.), Development of achievement motivation (pp. 249-284). Academic Press.

Savoji, A. P., Niusha, B., \& Boreiri, L. (2013). Relationship between epistemological beliefs, self-regulated learning strategies and academic achievement. Procedia-social and Behavioral Sciences, 84(9), 1160-1165.

Schommer, M. (1990). Effects of beliefs about the nature of knowledge on comprehension. Journal of Educational Psychology, 82(3), 498-504.

Schommer, M., Crouse, A., \& Rhodes, N. (1992). Epistemological beliefs and mathematical text comprehension: Believing it is simple does not make it so. Journal of Educational Psychology, 84(4), 435-443.

Schraw, G., Bendixen, L. D., \& Dunkle, M. E. (2002). Development and validation of the Epistemic Belief Inventory (EBI). In P. R. Pintrich (Ed.), Personal epistemology: The psychology of beliefs about knowledge and knowing (pp. 261-276). Lawrence Erlbaum Associates.

Stromso, H. I., \& Braten, I. (2010). The role of personal epistemology in the self-regulation of internet-based learning. Metacognition Learning, 5, 91-111.

Winne, P., \& Hadwin, A. F. (1998). Studying as self-regulated learning. In D. J. Hacker, J. Dunlosky, \& A. C. Graesser (Eds.), Metacognition educational theory and practice (pp.277-304). Erlbaum.

Youn, I. (2000). The culture specificity of epistemological beliefs about learning. Asian Journal of Social Psychology, 3, 87-105.

Zimmerman, B.J. (2000). Attainment of self-regulation: A social cognitive perspective. In M. Boekaerts, P.R. Pintrich, \& M. Zeidner (Eds.), Handbook of self-regulation (pp. 1339). Academic Press.

Received: $11-10-2020$

Accepted: 26-02-2021 